\title{
IGF-IR and its inhibitors in gastrointestinal carcinomas (Review)
}

\author{
XIAO HONG BAO ${ }^{1}$, YOSHIO NAOMOTO ${ }^{1}$, HUI FANG HAO ${ }^{1}$, NOBUYUKI WATANABE ${ }^{1}$, \\ KAZUFUMI SAKURAMA ${ }^{1}$, KAZUHIRO NOMA ${ }^{1}$, TAKAYUKI MOTOKI ${ }^{1}$, YASUKO TOMONO ${ }^{2}$, \\ TAKUYA FUKAZAWA ${ }^{1}$, YASUHIRO SHIRAKAWA ${ }^{1}$, TOMOKI YAMATSUJI ${ }^{1}$, \\ JUNJI MATSUOKA ${ }^{1}$ and MUNENORI TAKAOKA ${ }^{1}$
}

\author{
${ }^{1}$ Department of Gastroenterological Surgery, Transplant and Surgical Oncology, Graduate School of Medicine, \\ Dentistry and Pharmaceutical Sciences, Okayama University; ${ }^{2}$ Shigei Medical Research Institute, Okayama, Japan
}

Received June 17, 2009; Accepted September 7, 2009

DOI: 10.3892/ol_00000036

\begin{abstract}
The type I insulin-like growth factor receptor (IGF-IR) and its associated signaling system play a significant role in tumorigenesis, tumor survival and progression, and cancer therapeutic resistance, and thus has provoked great interest as a promising target for cancer treatment. In this report we present the role of IGF-IR in gastrointestinal carcinomas whose pathology has been identified as tightly correlated with an abnormal expression and activation of IGF-IR. Reported data from experimental studies suggest the feasibility of targeted IGF-IR therapy in gastrointestinal carcinomas. Many types of inhibitors against IGF-IR have been developed. Inhibitors with anti-IGF-IR monoclonal antibodies and tyrosine kinase inhibitors currently undergoing preclinical and clinical evolution are also reviewed.
\end{abstract}

\section{Contents}

1. Introduction

2. The role of type I insulin-like growth factor receptor in gastrointestinal cancers

3. Inhibitors targeting type I insulin-like growth factor receptor

4. Conclusion

Correspondence to: $\mathrm{Dr}$ Yoshio Naomoto, Department of Gastroenterological Surgery, Transplant and Surgical Oncology, Graduate School of Medicine, Dentistry and Pharmaceutical Sciences, Okayama University, 2-5-1 Shikata-cho, Okayama 700-8558, Japan E-mail: ynaomoto@md.okayama-u.ac.jp

Abbreviations: IGF, insulin-like growth factor; IGF-IR, type I insulin-like growth factor receptor; IGFBP, insulin-like growth factor binding proteins; ATP, adenosine triphosphate

Key words: type I insulin-like growth factor receptor, monoclonal antibody, tyrosine kinase inhibitor, gastrointestinal carcinoma, cancer therapy

\section{Introduction}

The insulin-like growth factor (IGF) signaling system is comprised of 2 cognate ligands (IGF-I and IGF-II), cell surface receptors (IGF-IR, IGF-IIR, IR and hybrid receptors) and at least 6 IGF binding proteins (IGFBPs) (1). Accumulated evidence has demonstrated that the signal transmitted by IGF-IR is required for normal cell growth, the development of tissues and the regulation of overall organism growth (2), and that its dysregulation is associated with tumorigenesis, cancer development and resistance to existing forms of cancer therapy in various diverse malignancies (3), including gastrointestinal cancers (4). IGFs are single chain polypeptides that share $40 \%$ homology with proinsulin in amino acid sequences (5). The biological role of IGFs in both normal and pathological cells is exerted by its binding with IGF-IR, which is a tetrameric transmembrane receptor tyrosine kinase, leading to autophosphorylation of IGF-IR and the activation of downstream cascades, including IRS (insulin receptor substrates 1-4) and Shc (Src homology and collagen domain protein). These early activations trigger multiple signaling pathways, including phosphatidylinositide 3-kinase (PI3K)/ Akt-1 (protein kinase B) pathways and the mitogen-activated protein kinase (MAPK) pathway $(6,7)$, playing an important role in cell proliferation, migration and metabolism. There are 3 key downstream protein kinases, ERK (extracellular signalregulated kinases), JNK (c-Jun amino-terminal kinases) and p38 protein kinases, which respectively contribute to cell division, protein transcription and various diseases such as asthma and autoimmunity (7).

Gastrointestinal carcinoma is one of the most common cancers that threatens human life. The recent consensus regarding the role of IGF signaling in initiating and promoting tumor progression makes it an attractive target for cancer therapy. Various strategies targeting IGF-IR are being developed that effectively inhibit tumor growth, metastasis and induce apoptosis, suggesting that IGF-IR is an attractive target for gastrointestinal cancers. Monoclonal antibodies and tyrosine kinase inhibitors against IGF-IR are two of the most effective strategies, especially monoclonal antibodies, some of which are advancing to clinical use. Due to the complexity of the IGF system and the diversity of inhibitors targeting IGF-IR 
that are being developed, this review introduces current evidence from preclinical and clinical studies that suggests the increasing role of IGF-IR in gastrointestinal cancers. We also present a review of ongoing inhibitors, monoclonal antibodies and tyrosine kinase inhibitors against IGF-IR in gastrointestinal cancers such as colorectal adenocarcinoma, pancreatic adenocarcinoma, esophageal squamous cell carcinoma and hepatoma, and discuss the potential effects of these inhibitors on anti-cancer treatment.

\section{The role of type I insulin-like growth factor receptor in gastrointestinal cancers}

Aberrant expression of type I insulin-like growth factor receptor is correlated with malignancy. Overexpression of IGF-IR has been reported in several types of gastrointestinal cancers. The expression level of IGF-IR in colon carcinomas can be detected by RT-PCR and immunohistochemistry at the nucleotide level and the protein level, respectively (8). The quantity of IGF-IR mRNA in colon cancers was found to be 2-fold higher than in adjacent normal mucosa in 32 of $40(80 \%)$ samples. Ninety-one percent of tumors (30 of 33) were IGF-IRpositive compared with the adjacent normal colonic epithelial cells that were IGF-IR-negative. These results confirmed the role of IGF-IR in the pathogenesis of colorectal cancer. Jiang et al found that IGF-IR was strongly expressed in $62 \%$ of gastric tumor tissue specimens via immunohistochemistry when compared with adjacent normal gastric mucosa, and its higher expression status was associated with increased lymph node metastasis (9). Sixty percent of human esophageal squamous cell carcinomas had strong immunoreactivity with an anti-IGF-IR antibody and correlated with metastasis, invasion depth, advanced tumor stage and recurrence (10). High expression levels of IGF-IR in pancreatic cancer (11) and hepatocellular carcinoma (12) were also reported, indicating that a high level of expression is related to angiogenesis, proliferation and survival.

The pathway of IGF-IR-mediated signaling has been summarized in several reviews, revealing that the IRS-1/PI3K/AKT and Shc/RAS/RAF/MEK/ERK axes are key downstream signaling pathways $(13,14)$. Furthermore, the specific regulatory mechanism of IGF-IR expression was reported on in pancreatic cancer, suggesting that IRS-2 is involved in the translational regulation of IGF-IR expression via PKCS and mTOR rather than AKT (15). Overexpression of a protein arises through the amplification of the gene or the increase in the binding strength of the promoter region. An increased number of copies of the IGF-IR gene, which is located at $15 \mathrm{q} 25 \sim$ qter, was found in human breast cancer $(16,17)$, pancreatic adenocarcinoma (18) and Wilms' tumors (19). However, its low frequency makes it uncommon ( $2 \%$ ). Recently, Meng et al studied the internal ribosomal entry site (IRES) of the 5'-untranslated region (5'-UTR) of human IGF-IR, indicating that its activity is aberrantly increased which enhances the translational efficiency in some human breast tumors compared with non-transformed human breast epithelial cells through an alteration in the activities of RNA-translation regulatory proteins (20). The transcription of IGF-IR mRNA might be regulated by Sp1, a transcription factor, since patients exhibiting strong expression of Sp1 also have active transcription of IGF-IR (9). Although there are few reports regarding the mechanism underlying the physiological dysregulation of IGF-IR, it is clear that there is great complexity in the patterns of its overexpression in tumors of different origins.

Rigorous, prospective research has found a consistent correlation between the circulating IGF-I level and cancer risk in various malignancies of the gastrointestinal tract, e.g. colorectal carcinoma (21) and prostate carcinoma (22). These studies showed that individuals at the high end of the normal range of serum IGF-I concentration and/or lower levels of IGFBPs had more than double the risk of a subsequent cancer diagnosis than those at the low end of the normal range. Imsumran et al revealed that expression of IGF-IR/IGF-IIR in esophageal squamous cell carcinoma was observed in more than half of the tumors and markedly correlated with clinicopathological characteristics (e.g. depth of invasion, lymph node metastasis, distant metastasis, advanced pTNM stage and recurrence), concluding that expression of IGF-IR/IGF-II may be useful for the prediction of recurrence and poor prognosis (10). Notably, a study of specimens from 161 patients with curatively resected Dukes' C colorectal cancer (CRC) using immunohistochemistry detected focal staining membrane IGF-IR (low expression level) in $72 \%$ of specimens, while diffuse staining membrane IGF-IR (high expression level) was detected in $28 \%$. The recurrence rate was significantly higher in the focal staining group than in the diffuse staining group. This indicates that low IGF-IR membrane expression in Dukes' C CRC may be a predictor of a high risk of metastasis (23). Use of the expression level of IGF-IR as a tumor marker or as a risk factor varies among studies, perhaps due to imperfect measurement methodology or the different cellular microenvironment of tumors or IGF-IR levels related to a specific subset of patients.

Type I insulin-like growth factor receptor is a promising target in gastrointestinal carcinomas. The effects of blocking the function of IGF-IR have been confirmed by studies conducted over the last two decades. In a variety of in vitro and in vivo models, an interruption of IGF-mediated signaling has been demonstrated to induce apoptosis, inhibit tumor growth and migration, and augment the response to other forms of cancer therapy. In this section we discuss data from recent studies on the effects of the down-regulation of IGF-IR in gastrointestinal cancers, confirming that IGF-IR is a therapeutic target for cancer therapy. These studies demonstrated that, in accumulated experimental settings, interference with the IGF-IR function leads to the inhibition of cancer cell proliferation, survival, anchorage-independent growth in vitro and leads to the inhibition of tumor growth and the metastasis and sensitization of the cancer cells to various chemotherapeutic and radiation treatments in vivo.

There are many effectors to regulate cell growth and proliferation. IGF-IR is not unique in propelling tumor cell proliferation, but it is indispensable for mediating the proliferation and survival of tumor cells for anchorage-independent growth. In vitro, blocking IGF-IR, using its specific tyrosine kinase inhibitor NVP-AEW541, potently inhibited the cell proliferation of gastrointestinal neuroendocrine tumors (NET) and CRC by inducing apoptosis, which was characterized by the activation of caspase 3 and the expression of BAX and $\mathrm{Bcl}-2$, and by cell cycle arrest at the G1/S checkpoint in both 
primary and permanent NET and CRC, respectively $(24,25)$. In vivo, the tyrosine kinase activation of IGF-IR inhibited by small molecular inhibitor led to a significant reduction of HT29 tumor growth in nude mice (26), further confirming its essential role in tumor growth.

Components of the IGF-I/IGF-IR signaling system are important mediators of tumor cell migration and invasion. Recent research showed that IGF-I-mediated migration and invasion were mostly inhibited via the down-regulation of c-Met with ribozyme-expressing adenovirus, suggesting that IGF-IR signaling cooperates with c-Met signaling to induce migration and invasion of human pancreatic carcinoma cells (27). That IGF-IR regulates the liver metastasis of colon cancer cells was strongly confirmed by the observation that colon cancer cells with dominant negative IGF-IR failed to produce liver metastases after splenic injection (28).

Resistance to clinically useful anti-cancer therapies such as chemotherapy and radiation is a common occurrence among patients suffered from cancer. IGF-IR is tightly correlated with resistance to the cytotoxic effects of chemotherapy due to the protection of tumor cells against apoptosis through the PI3K/AKT pathway and the cytostatic effects via the MAPK pathway (29). There is considerable evidence to confirm the viewpoint that IGF-IR inhibition enhances the activity of cytotoxic chemotherapy and radiation. In rectal adenocarcinoma for example, the activation of the IGF-IR-mediated signal by IGF-I reduced the expected cytotoxicity of 5-FU, resulting in a 10 -fold increase in the $\mathrm{IC}_{50}$, however, the cytotoxic effect of 5-FU was enhanced in conjunction with an IGF-IR monoclonal antibody (30). The combination of IGF-IR inhibitor NVPAEW541 and the chemotherapy drugs cisplatin and 5-FU in gastrointestinal carcinoma cells significantly enhanced the effect of cisplatin and increased chemotherapy-induced apoptosis (26). Similarly, in the presence of the unique receptor inhibitor IGF-Ir/dn (dominant negative), which was constructed to inhibit the function rather than the expression of wild-type IGF-IR, both radiation- and chemotherapy-induced apoptosis increased significantly in treated gastric cancer cells, and the effect of chemotherapy in combination with IGF-Ir/dn on the suppression of tumor growth was remarkably augmented in pre-existing tumors in mice (31).

Based on the above data, IGF-IR mediates proliferation, motility and protection from apoptosis in cancer, and IGF-IR blockage can effectively suppress its role in gastrointestinal malignant transformation and progression. IGF-IR may thus have therapeutic use for gastrointestinal carcinomas.

\section{Inhibitors targeting type I insulin-like growth factor receptor}

Unlike members of the epidermal growth factor family, overexpression of IGF-IR is not sufficient to induce its phosphorylation, and its activation requires ligand stimulation. Therefore, the optimal strategy for interfering with the function of IGF-IR may be the inhibition of ligand-receptor interaction. When developing inhibitors targeting IGF-IR, the high homology between IGF-IR and IR, which share a high sequence identity (84\%) at the kinase domains and especially at the ATP-binding pocket (100\%) (32), should also be considered, as IR plays a critical role in glucose homeostasis and its blocking may lead to various diseases such as type 2 diabetes. Various strategies have been used to block IGF-IR and some of them are in clinical use (33). These strategies include the down-regulation of IGF-IR by single-chain antibodies, antisense oligonucleotides, triple helix-forming oligodeoxynucleotides, antisense RNA, small interfering RNA, fully humanized anti-IGF-IR monoclonal antibodies and specific kinase inhibitors. Furthermore, the neutralization of ligands can also inhibit the activity of IGF-IR because it is activated predominantly after binding to the cognate ligands. There are three ways to neutralize the action of IGF: overexpression of IGF-IIR (specifically binds to IGF-II) (34) and IGFBP-3 (35), the creation of soluble IGF-IR (e.g. IGF$1 \mathrm{R}^{933}$ ) and antibodies against IGF-I and IGF-II (e.g. KM1468, a rat monoclonal antibody) (36).

Among the various strategies mentioned above, the two most investigated strategies are tyrosine kinase inhibitors and monoclonal antibodies. Both have various advantages and show different activity profiles which have been confirmed by an abundance of data. Tyrosine kinase inhibitors are orally available and more easily penetrate the blood-brain barrier as they possess a small molecular size, while monoclonal antibodies are more likely to be selective to the target, which may avoid toxicities caused by inhibition of insulin receptors. On the other hand, the wider spectrum of characteristics of tyrosine kinase inhibitors might have alternative benefits due to the common expression of insulin receptors on cancers, hyperinsulinism in aggressive cancer and insulin-receptormediated resistance to IGF-IR-targeting therapy. In these cases, small molecular inhibitors may induce anti-neoplastic activity superior to that of the antibodies (37).

Currently, more than 25 molecules are at different stages of development (38). The clinical and preclinical development of both approaches is discussed, and various inhibitors will be reviewed below.

Anti-type I insulin-like growth factor receptor monoclonal antibodies. Numerous antibodies have been developed by pharmaceutical companies and have been proven effective in preclinical experiments. They subsequently have proceeded to clinical trials. Although generated using different strategies, these antagonists targeting the extracellular domain of IGF-IR specifically bind to IGF-IR, effectively interrupting the signal transformation by IGF-IR.

CP-751,871. Pfizer's CP-751,871, a fully human IgG2 antibody with a high affinity for human IGF-IR, is a product of XenoMouse technology. Currently, phase I and II clinical trials of CP-751,871 are underway in patients with multiple myeloma and non-small cell lung cancer (NSCLC) respectively, suggesting it may be a safe, tolerable and effective antagonist against IGF-IR $(39,40)$. It is also the first inhibitor targeting IGF-IR to initiate a phase III trial in NSCLC. In preclinical experiments, CP-751,871 inhibited the interaction of the IGF-IR with the IGF-I ligand and the autophosphorylation of IGF-IR induced by IGF-I and IGF-II. Internalization of IGF-IR by binding to CP-751,871 leads to the down-regulation of IGF-IRmediated signaling through a decrease in the phosphorylation of AKT. As a single agent, CP-751,871 significantly inhibited the growth of tumor xenograft models derived from colon 
(Colo-205), lung (H460) and breast (MCF7) cancer cell lines, showing anti-tumor efficacy that improved by combination treatment with standard chemotherapeutic agent 5-FU (41).

IMC-A12. ImClone Systems Inc.'s IMC-A12, another fully human IgG1 antibody, generated by screening a human Fab phage display library, selectively binds to IGF-IR (4.11 $\left.\times 10^{-11} \mathrm{~mol} / 1, \quad \mathrm{IC}_{50} 0.6-1 \mathrm{nmol} / \mathrm{l}\right)$ without interrupting insulin binding to the insulin receptor. The role of IGFs in proliferation and mitosis was antagonized by IMC-A12 via inhibiting 2-key downstream signaling of IGF-IR, MAPK and PI3K/AKT. A xenograft tumor model experiment demonstrated that IMC-A12 possesses high efficacy of growth inhibition of breast, pancreatic and colon tumors (42). As a signal agent, IMC-A12 has anti-tumor activity. It is well known that a combination therapy of IGF-IR-specific inhibitors and most classes of nonspecific chemotherapeutic agents or radiation may yield augmented anti-cancer efficacy over conventional treatments alone. Combining IMC-A12 with radiation significantly enhanced radiation-induced apoptosis, clonogenic survival and the growth inhibition of tumor xenografts (43). Markedly enhanced effects of either bortezomib or melphalan on decreasing the tumor burden and prolonging survival were demonstrated when combined with IMC-A12 (44). In addition, co-treatment with IMC-A12 and cetuximab (an anti-epidermal growth factor receptor antibody) in human tumor xenografts derived from colorectal and pancreatic tissues, showed impressive anti-tumor effects, confirming the therapeutic effects of targeting IGF-IR-mediated signaling and other signaling pathways associated with tumor growth and survival $(45,46)$. The phase I and II clinical trials of IMC-A12 demonstrated favorable, safe pharmacokinetic profiles. A phase II study is in progress in certain gastrointestinal cancers including colorectal, pancreatic and liver cancer (http://www. imclone.com).

MK-0646. MK-0646, also known as h7C10 or F50035, a recombinant humanized IgG1 anti-IGF-IR antibody, blocks cell proliferation induced by IGF-I and IGF-II, inhibits IGF-IR phosphorylation in a dose-dependent manner, interrupts IGF-I-induced activation of PI3K/AKT and MAPK pathways, induces both internalization and degradation of IGF-IR resulting in the decrease in the number of available binding sites for the cognate ligands on the cell surface $(47,48)$. This antibody exhibits potent anti-tumor efficacy in well-established tumor models. Like other inhibitors against IGF-IR, combined therapy with either a chemotherapeutic agent or an agent that specifically thwarts other signal transduction pathways, such as an epidermal growth factor receptor, may be more effective in the treatment of cancer than when used alone. Prolonged survival was observed when mice were simultaneous treated with MK-0646 and either vinorelbine or the EGFR antibody 225 (47). Recently, Pandini et al found that, besides IGF-IR, this antibody recognizes and specifically binds hybrid receptors composed of IGF-IR and IR without affecting IR, and in vivo displays efficacious anti-tumor activity to hybrid receptor down-regulation and degradation (49). It may also exert more therapeutic effects than blocking only IGF-IR, particularly in tumors with a high hybrid: IGF-IR ratio. A phase I study of MK-0646 in advanced solid tumor patients is in progress.
Tyrosine kinase inhibitors. To inhibit the tyrosine kinase activity of IGF-IR is another strategy of IGF-IR-targeted therapy. There are several tyrosine kinase inhibitors against IGF-IR in preclinical and clinical development. According to the characteristics of inhibitors to ATP, tyrosine kinase inhibitors may be divided into two categories: ATP antagonists and non-ATP antagonists. Most of the inhibitors belong to the former group. Pharmacologic studies demonstrated that the selectivity of these agents to IGF-IR over IR varies in vitro. OSI-906, NVP-AEW541, picropodophyllin and INSM-18 seem to be more selective for IGF-IR. BMS-554417, however, has a similar potency toward both receptors. The difference in selectivity of each receptor defines the specific therapeutic window for each drug.

INSM-18 (nordihydroguaiaretic acid). INSM-18 (nordihydroguaiaretic acid, NDGA), a naturally occurring compound isolated from the creosote bush Larrea divaricatta, is the only tyrosine kinase inhibitor of IGF-IR that has progressed to a clinical phase I trial for prostate cancer. It possesses co-targeting properties that directly inhibit IGF-IR tyrosine kinase and epidermal growth factor receptors, the c-erbB2/ HER2/neu (HER2/neu) receptor in human breast cancer (50), including tamoxifen or trastuzumab refractory HER2overexpressing breast cancer cells $(51,52)$. The mechanism involved in the inhibition of IGF-IR activation is not yet known. INSM-18 promotes cell death via the induction of apoptosis which is detected by the activation of caspase 3 and PARP in trastuzumab-resistant HER2-overexpressing breast cancer cells (52). In preclinical studies, the anti-tumor activity of INSM-18 has been demonstrated in breast, prostate, pancreatic and lung tumors. The safety and tolerability of this agent have been documented in two single-dose phase I clinical studies in healthy volunteers (http://www.insmed.com/oncology.php). Moreover, Ryan et al in a dose-escalating (750, 1250, 1750, 2250 and $2500 \mathrm{mg}$ of NDGA) phase I and II clinical study in patients with relapsed prostate cancer found that, although no other toxicity was found in patients receiving an oral daily dose of NDGA up to $2500 \mathrm{mg}$, transaminitis occurred in some patients (53). This finding will lead to further study in order to evaluate the optimum pharmacokinetics and anti-tumor efficacy of NDGA.

NVP-AEW541. NVP-AEW541 belongs to the pyrrolo [2, 3-d] pyrimidine class and is a new, orally bioavailable small molecular inhibitor of IGF-IR tyrosine kinase (54). Currently, studies of this inhibitor are in the preclinical stage, focusing on its effects on growth inhibition, the induction of apoptosis in various tumor cells in vitro and anti-tumor activities in vivo. NVP-AEW541 has been confirmed as highly selective towards IGF-IR kinase with an $\mathrm{IC}_{50}$ value of $0.086 \mu \mathrm{M}$ over IR kinase with an $\mathrm{IC}_{50}$ value of $2.3 \mu \mathrm{M}$ (54). Several malignancies of the gastrointestinal tract, such as CRC (25), gastrointestinal stromal tumors (26), gastrointestinal NET (24), pancreatic cancer (55) and hepatocellular carcinoma (HCC) (56), were employed to study the anti-neoplastic potency of NVPAEW541 and the associated signaling cascade after IGF-IR blocking with NVP-AEW541. For instance, in pancreatic cancer cells NVP-AEW541 interfered with the signal transduction, which is known to be involved in IGF/IGF-IR 
signaling, through inhibiting the activation of IRS-1, ERK, AKT and transcription factor STAT3. Regarding the potential cytotoxic effect of this chemical compound and cell motility, NVP-AEW541 decreased pancreatic cancer cell growth and abrogated migration mediated by IGF-I. An orthotopic model of pancreatic cancer was established to assess the in vivo effects of NVP-AEW541 in the appropriate tumor microenvironment, and the results revealed that the blocking of IGF-IR with NVP-AEW541 harbours the potential to effectively inhibit the growth and vascularization of human pancreatic cancer. As a single agent, NVP-AEW541 may be effective against various types of malignancies; however its therapeutic effects may be augmented by combination with nonspecific cytotoxic or targeted therapeutics, since IGF-IR is closely related with cell survival, anti-apoptosis and resistance to the cytotoxic effects of radiation and chemotherapy. Combinational treatment of NET cells with NVP-AEW541 and the cytostatic drugs doxorubicin or HMG-CoA (3-hydroxy-3-methylglutaryl coenzyme A) reductase inhibitor, fluvastatin, enhanced the anti-proliferative effect of NVP-AEW541 (24). Simultaneous blockage of IGF-IR and EGFR by IGF-IR tyrosine kinase inhibitors NVP-AEW541 and EGFR tyrosine kinase inhibitors erlotinib in colorectal cancer impaired the cell proliferation more effectively than did blocking with either inhibitor alone, suggesting that combination therapy targeting IGF-IR and EGFR might be feasible in clinical application (57). Taken together, NVP-AEW541 may have potential therapeutic utility in the treatment of gastrointestinal tumors for which IGF-IRmediated signaling is essential for survival and proliferation.

BVP-51004 (PPP). BVP-51004, also named PPP, is a cyclolignan-derivative picropodophyllin. It was originally identified at the Karolinska Cancer Institute (Sweden) and is currently being developed by Biovitrum. Most of the identified small molecular inhibitors against IGF-IR belonging to ATP competitive inhibitors might inhibit the activation of insulin receptors due to the high homology of ATP binding sites of IGF-IR and insulin receptor kinase $(32,58)$, coinhibition of which may cause diabetic response. PPP, however, is an ATP non-competitive IGF-IR inhibitor and exerts its function through inhibiting Tyr1136 phosphorylation in the activation loop of IGF-IR kinase, which contributes to stabilize the conformation of the activation loop $(59,60)$. PPP causes tumor regression in murine xenograft models (e.g. multiple myeloma and HCC mice) $(61,62)$, and is well-tolerated in vivo as shown by the fact that the survival of the mice bearing multiple myeloma treated with PPP was prolonged by almost 3 months compared with the control group (63). It has been shown that PPP also down-regulates IGF-IR leading to the apoptosis of tumor cells without affecting the highly homologous insulin receptor (64). The cytotoxicity of PPP is associated with the inhibition of AKT activation, with temporary stimulation of ERK activation via IGF-IR ubiquitination. This is a novel aspect of mechanism of PPP action, interfering with the two major signaling branches of the IGF-IR cascade through different mechanisms (65). Notably, IGF-IR-deficient R-cells, exposed to PPP, were sensitive to PPP, which is inconsistent with the its potential as a IGF-IR-specific inhibitor (66). Thus, the mechanism of PPP action need to be further elucidated.

\section{Conclusion}

Signal transduction via IGF-IR is associated with cell proliferation, anti-apoptosis, metastasis, tumorigenesis and resistance to cytotoxic cancer therapies. The role IGF-IR plays in driving tumor cell survival has been demonstrated in many different types of tumors, including gastrointestinal malignancies, and targeting IGF-IR by a variety of approaches, particularly monoclonal antibodies and small molecule tyrosine kinase inhibitors, may be some of the most effective ways to treat cancer. This has been confirmed by accumulated data from preclinical and early clinical trials. In view of the complexity of roles of the IGF axis in both normal and malignant cells, it is crucial to know that the properties of agents against IGF-IR do not impede normal physiology while exhibiting high toxicity to cancer cells. Thus, careful attention must be paid to the dose effect and the potential side effects resulting from the administration of IGF-IR inhibitors. Also, combination therapy with conventional cytotoxic therapy may be more effective than inhibitors alone. Therefore, selecting suitable combinations must be the focus of future clinical trials. Final evaluations for all of the therapeutics described here are forthcoming from the results of clinical trials.

\section{References}

1. Ryan PD and Goss PE: The emerging role of the insulin-like growth factor pathway as a therapeutic target in cancer. Oncologist 13: 16-24, 2008.

2. Miller BS and Yee D: Type I insulin-like growth factor receptor as a therapeutic target in cancer. Cancer Res 65: 10123-10127, 2005.

3. Baserga R: Oncogenes and the strategy of growth factors. Cell 79: 927-930, 1994.

4. Adachi Y, Yamamoto H, Imsumran A, et al: Insulin-like growth factor-I receptor as a candidate for a novel molecular target in the gastrointestinal cancers. Dig Endosc 18: 245-251, 2006.

5. Furstenberger G and Senn HJ: Insulin-like growth factors and cancer. Lancet Oncol 3: 298-302, 2002.

6. Manning BD and Cantley LC: AKT/PKB signaling: navigating downstream. Cell 129: 1261-1274, 2007.

7. Johnson GL and Lapadat R: Mitogen-activated protein kinase pathways mediated by ERK, JNK and p38 protein kinases. Science 298: 1911-1912, 2002.

8. Weber MM, Fottner C, Liu SB, Jung MC, Engelhardt D and Baretton GB: Overexpression of the insulin-like growth factor I receptor in human colon carcinomas. Cancer 95: 2086-2095, 2002.

9. Jiang Y, Wang L, Gong W, Wei D, Le X, Yao J, Ajani J, Abbruzzese JL, Huang S and Xie K: A high expression level of insulin-like growth factor I receptor is associated with increased expression of transcription factor $\mathrm{Sp} 1$ and regional lymph node metastasis of human gastric cancer. Clin Exp Metastasis 21: 755-764, 2004.

10. Imsumran A, Adachi Y, Yamamoto H, et al: Insulin-like growth factor-I receptor as a marker for prognosis and a therapeutic target in human esophageal squamous cell carcinoma. Carcinogenesis 28: 947-956, 2007.

11. Bergmann U, Funatomi H, Yokoyama M, Beger HG and Korc M: Insulin-like growth factor I overexpression in human pancreatic cancer: evidence for autocrine and paracrine roles. Cancer Res 55: 2007-2011, 1995.

12. Zhang YC, Wang XP, Zhang LY, Song AL, Kou ZM and Li XS: Effect of blocking IGF-I receptor on growth of human hepatocellular carcinoma cells. World J Gastroenterol 12: 3977-3982, 2006.

13. Samani AA, Yakar S, LeRoith D and Brodt P: The role of the IGF system in cancer growth and metastasis: overview and recent insights. Endocrine 28: 20-47, 2007.

14. Chitnis MM, Yuen JS, Protheroe AS, Pollak M and Macaulay VM: The type 1 insulin-like growth factor receptor pathway. Clin Cancer Res 14: 6364-6370, 2008. 
15. Kwon J, Stephan S, Mukhopadhyay A, Muders MH, Dutta SK, Lau JS and Mukhopadhyay D: Insulin receptor substrate-2mediated insulin-like growth factor-I receptor overexpression in pancreatic adenocarcinoma through protein kinase Cdelta. Cancer Res 69: 1350-1357, 2009.

16. Almeida A, Muleris M, Dutrillaux B and Malfoy B: The insulinlike growth factor I receptor gene is the target for the $15 \mathrm{q} 26$ amplicon in breast cancer. Genes Chromosomes Cancer 11: 63-65, 1994.

17. Berns EM, Klijn JG, van Staveren IL, Portengen H and Foekens JA: Sporadic amplification of the insulin-like growth factor 1 receptor gene in human breast tumors. Cancer Res 52: 1036-1039, 1992.

18. Armengol G, Knuutila S, Lluís F, Capellà G, Miró R and Caballín MR: DNA copy number changes and evaluation of MYC, IGF1R and FES amplification in xenografts of pancreatic adenocarcinoma. Cancer Genet Cytogenet 116: 133-141, 2000.

19. Natrajan R, Reis-Filho JS, Little SE, Messahel B, Brundler MA, Dome JS, Grundy PE, Vujanic GM, Pritchard-Jones K and Jones C: Blastemal expression of type I insulin-like growth factor receptor in Wilms' tumors is driven by increased copy number and correlates with relapse. Cancer Res 66: 11148-11155, 2006.

20. Meng Z, Jackson NL, Choi H, King PH, Emanuel PD and Blume SW: Alterations in RNA-binding activities of IRESregulatory proteins as a mechanism for physiological variability and pathological dys-regulation of IGF-IR translational control in human breast tumor cells. J Cell Physiol 217: 172-183, 2008.

21. Stattin P, Bylund A, Rinaldi S, Biessy C, Dechaud H, Stenman UH, Egevad L, Riboli E, Hallmans G and Kaaks R: Plasma insulinlike growth factor-I, insulin-like growth factor-binding proteins, and prostate cancer risk: a prospective study. J Natl Cancer Inst 92: 1910-1917, 2000.

22. Palmqvist R, Hallmans G, Rinaldi S, Biessy C, Stenling R, Riboli E and Kaaks R: Plasma insulin-like growth factor 1, insulin-like growth factor binding protein 3 and risk of colorectal cancer: a prospective study in northern Sweden. Gut 50: 642-646, 2002.

23. Nakamura M, Miyamoto S, Maeda H, Zhang SC, Sangai T, Ishii G, Hasebe T, Endoh Y, Saito N, Asaka M and Ochiai A: Low levels of insulin-like growth factor type 1 receptor expression at cancer cell membrane predict liver metastasis in Dukes' $\mathrm{C}$ human colorectal cancers. Clin Cancer Res 10: 8434-8441, 2004.

24. Höpfner M, Baradari V, Huether A, Schöfl C and Scherübl H: The insulin-like growth factor receptor 1 is a promising target for novel treatment approaches in neuroendocrine gastrointestinal tumours. Endocr Relat Cancer 13: 135-149, 2006.

25. Hopfner M, Sutter AP, Huether A, Baradari V and Scherubl H: Tyrosine kinase of insulin-like growth factor receptor as target for novel treatment and prevention strategies of colorectal cancer. World J Gastroenterol 12: 5635-5643, 2006.

26. Piao W, Wang Y, Adachi Y, et al: Insulin-like growth factor-I receptor blockade by a specific tyrosine kinase inhibitor for human gastrointestinal carcinomas. Mol Cancer Ther 7: 1483-1493, 2008.

27. Bauer TW, Somcio RJ, Fan F, Liu W, Johnson M, Lesslie DP, Evans DB, Gallick GE and Ellis LM: Regulatory role of c-Met in insulin-like growth factor-I receptor-mediated migration and invasion of human pancreatic carcinoma cells. Mol Cancer Ther 5: 1676-1682, 2006.

28. Reinmuth N, Fan F, Liu W, Parikh AA, Stoeltzing O, Jung YD, Bucana CD, Radinsky R, Gallick GE and Ellis LM: Impact of insulin-like growth factor receptor-I function on angiogenesis, growth and metastasis of colon cancer. Lab Invest 82: 1377-1389, 2002.

29. Gooch JL, van Den Berg CL and Yee D: Insulin-like growth factor (IGF)-I rescues breast cancer cells from chemotherapy-induced cell death-proliferative and anti-apoptotic effects. Breast Cancer Res Treat 56: 1-10, 1999.

30. Perer ES, Madan AK, Shurin A, Zakris E, Romeguera K, Pang Y and Beech DJ: Insulin-like growth factor I receptor antagonism augments response to chemoradiation therapy in colon cancer cells. J Surg Res 94: 1-5, 2000.

31. Min Y, Adachi Y, Yamamoto H, Imsumran A, Arimura Y, Endo T, Hinoda Y, Lee CT, Nadaf S, Carbone DP and Imai K: Insulin-like growth factor I receptor blockade enhances chemotherapy and radiation responses and inhibits tumour growth in human gastric cancer xenografts. Gut 54: 591-600, 2005.
32. Ullrich A, Gray A, Tam AW, et al: Insulin-like growth factor I receptor primary structure: comparison with insulin receptor suggests structural determinants that define functional specificity. EMBO J 5: 2503-2512, 1986.

33. Hofmann $\mathrm{F}$ and Garcia-Echeverria $\mathrm{C}$ : Blocking the insulin-like growth factor-I receptor as a strategy for targeting cancer. Drug Discov Today 10: 1041-1047, 2005.

34. Lee JS, Weiss J, Martin JL and Scott CD: Increased expression of the mannose 6-phosphate/insulin-like growth factor-II receptor in breast cancer cells alters tumorigenic properties in vitro and in vivo. Int J Cancer 107: 564-570, 2003.

35. Zhang $X$ and Yee D: Insulin-like growth factor binding protein-1 (IGFBP-1) inhibits breast cancer cell motility. Cancer Res 62: 4369-4375, 2002.

36. Goya M, Miyamoto S, Nagai K, et al: Growth inhibition of human prostate cancer cells in human adult bone implanted into nonobese diabetic/severe combined immunodeficient mice by a ligand-specific antibody to human insulin-like growth factors. Cancer Res 64: 6252-6258, 2004.

37. Pollak M: Insulin, insulin-like growth factors and neoplasia. Best Pract Res Clin Endocrinol Metab 22: 625-638, 2008.

38. Rodon J, DeSantos V, Ferry RJ Jr and Kurzrock R: Early drug development of inhibitors of the insulin-like growth factor-I receptor pathway: lessons from the first clinical trials. Mol Cancer Ther 7: 2575-2588, 2008.

39. Lacy MQ, Alsina M, Fonseca R, Paccagnella ML, Melvin CL, Yin D, Sharma A, Enriquez Sarano M, Pollak M, Jagannath S, Richardson P and Gualberto A: Phase I, pharmacokinetic and pharmacodynamic study of the anti-insulin-like growth factor type 1 receptor monoclonal antibody CP-751,871 in patients with multiple myeloma. J Clin Oncol 26: 3196-3203, 2008.

40. Karp DD, Paz-Ares LG, Novello S, Haluska P, Garland L, Cardenal F, Blakely LJ, Eisenberg PD, Langer CJ, Blumenschein G Jr, Johnson FM, Green S and Gualberto A: Phase II study of the anti-insulin-like growth factor type 1 receptor antibody CP-751,871 in combination with paclitaxel and carboplatin in previously untreated, locally advanced, or metastatic non-small cell lung cancer. J Clin Oncol 27: 2516-2522, 2009.

41. Cohen BD, Baker DA, Soderstrom C, Tkalcevic G, Rossi AM, Miller PE, Tengowski MW, Wang F, Gualberto A, Beebe JS and Moyer JD: Combination therapy enhances the inhibition of tumor growth with the fully human anti-type 1 insulin-like growth factor receptor monoclonal antibody CP-751,871. Clin Cancer Res 11: 2063-2073. 2005.

42. Burtrum D, Zhu Z, Lu D, et al: A fully human monoclonal antibody to the insulin-like growth factor I receptor blocks ligand-dependent signaling and inhibits human tumor growth in vivo. Cancer Res 63: 8912-8921, 2003.

43. Allen GW, Saba C, Armstrong EA, Huang SM, Benavente S, Ludwig DL, Hicklin DJ and Harari PM: Insulin-like growth factor-I receptor signaling blockade combined with radiation. Cancer Res 67: 1155-1162, 2007.

44. Wu KD, Zhou L, Burtrum D, Ludwig DL and Moore MA: Antibody targeting of the insulin-like growth factor I receptor enhances the anti-tumor response of multiple myeloma to chemotherapy through inhibition of tumor proliferation and angiogenesis. Cancer Immunol Immunother 56: 343-357, 2007.

45. Prewett M, Damoci C, Bassi R, Ludwig DL, Hicklin DJ and Tonra JR: IMC-A12 enhances the efficacy of cetuximab + gemcitabine therapy in human pancreatic carcinoma xenografts. Proc Am Assoc Cancer Res 48: 652, 2007.

46. Tonra JR, Corcoran E, Makhoul G, et al: Synergistic anti-tumor effects of anti-EGFR monoclonal antibody Erbitux ${ }^{\circledR}$ combined with antibodies targeting IGF1R or VEGFR-2. Proc Am Assoc Cancer Res 46: 1193, 2005.

47. Goetsch L, Gonzalez A, Leger O, Beck A, Pauwels PJ, Haeuw JF and Corvaia N: A recombinant humanized anti-insulin-like growth factor receptor type I antibody (h7C10) enhances the antitumor activity of vinorelbine and anti-epidermal growth factor receptor therapy against human cancer xenografts. Int $\mathbf{J}$ Cancer 113: 316-328, 2005.

48. Broussas M, Dupont J, Gonzalez A, Blaecke A, Fournier M, Corvaïa $\mathrm{N}$ and Goetsch L: Molecular mechanisms involved in activity of h7C10, a humanized monoclonal antibody, to IGF-1 receptor. Int J Cancer 124: 2281-2293, 2009. 
49. Pandini G, Wurch T, Akla B, et al: Functional responses and in vivo anti-tumour activity of h7C10: a humanised monoclonal antibody with neutralising activity against the insulin-like growth factor-1 (IGF-1) receptor and insulin/IGF-1 hybrid receptors. Eur J Cancer 43: 1318-1327, 2007.

50. Youngren JF, Gable K, Penaranda C, Maddux BA, Zavodovskaya $\mathrm{M}$, Lobo $\mathrm{M}$, Campbell $\mathrm{M}$, Kerner $\mathrm{J}$ and Goldfine ID: Nordihydroguaiaretic acid (NDGA) inhibits the IGF-1 and c-erbB2/HER2/neu receptors and suppresses growth in breast cancer cells. Breast Cancer Res Treat 94: 37-46, 2005.

51. Zavodovskaya M, Campbell MJ, Maddux BA, Shiry L, Allan G, Hodges L, Kushner P, Kerner JA, Youngren JF and Goldfine ID: Nordihydroguaiaretic acid (NDGA), an inhibitor of the HER2 and IGF-1 receptor tyrosine kinases, blocks the growth of HER2 overexpressing human breast cancer cells. J Cell Biochem 103: 624-635, 2008 .

52. Rowe DL, Ozbay T,BenderLM and NahtaR:Nordihydroguaiaretic acid, a cytotoxic insulin-like growth factor-I receptor/HER2 inhibitor in trastuzumab-resistant breast cancer. Mol Cancer Ther 7: 1900-1908, 2008.

53. Ryan CJ, Harzstark AH, Rosenberg J, Lin A, Claros C, Goldfine ID, Kerner JF, Small EJ and Youngren JF: A pilot doseescalation study of the effects of nordihydroguareacetic acid on hormone and prostate specific antigen levels in patients with relapsed prostate cancer. BJU Int 101: 436-439, 2008.

54. Garcia-Echeverria C, Pearson MA, Marti A, et al: In vivo antitumor activity of NVP-AEW541 - a novel, potent and selective inhibitor of the IGF-IR kinase. Cancer Cell 53: 231-239, 2004.

55. Moser C, Schachtschneider P, Lang SA, Gaumann A, Mori A, Zimmermann J, Schlitt HJ, Geissler EK and Stoeltzing O: Inhibition of insulin-like growth factor-I receptor (IGF-IR) using NVP-AEW541, a small molecule kinase inhibitor, reduces orthotopic pancreatic cancer growth and angiogenesis. Eur J Cancer 44: 1577-1586, 2008.

56. Höpfner M, Huether A, Sutter AP, Baradari V, Schuppan D and Scherübl H: Blockade of IGF-1 receptor tyrosine kinase has antineoplastic effects in hepatocellular carcinoma cells. Bio Chem Pharmacol 71: 1435-1448, 2006.

57. Kaulfuss S, Burfeind P, Gaedcke J and Scharf JG: Dual silencing of insulin-like growth factor-I receptor and epidermal growth factor receptor in colorectal cancer cells is associated with decreased proliferation and enhanced apoptosis. Mol Cancer Ther 8: 821-833, 2009.
58. Favelyukis S, Till JH, Hubbard SR and Miller WT: Structure and autoregulation of the insulin-like growth factor 1 receptor kinase. Nat Struct Biol 8: 1058-1063, 2001.

59. Girnita A, Girnita L, del Prete F, Bartolazzi A, Larsson O and Axelson M: Cyclolignans as inhibitors of the insulin-like growth factor-1 receptor and malignant cell growth. Cancer Res 64: 236-242, 2004.

60. Vasilcanu D, Girnita A, Girnita L, Vasilcanu R, Axelson M and Larsson O: The cyclolignan PPP induces activation loop-specific inhibition of tyrosine phosphorylation of the insulin-like growth factor-1 receptor. Link to the phosphatidyl inositol-3 kinase/Akt apoptotic pathway. Oncogene 23: 7854-7862, 2004.

61. Menu E, Jernberg-Wiklund H, Stromberg T, de Raeve H, Girnita L, Larsson O, Axelson M, Asosingh K, Nilsson K, van Camp B and Vanderkerken K: Inhibiting the IGF-1 receptor tyrosine kinase with the cyclolignan PPP: an in vitro and in vivo study in the 5T33MM mouse model. Blood 107: 655-660, 2006.

62. Nussbaum T, Samarin J, Ehemann V, Bissinger M, Ryschich E, Khamidjanov A, Yu X, Gretz N, Schirmacher P and Breuhahn K: Autocrine insulin-like growth factor-II stimulation of tumor cell migration is a progression step in human hepatocarcinogenesis. Hepatology 48: 146-156, 2008.

63. Menu E, Jernberg-Wiklund $\mathrm{H}$, de Raeve $\mathrm{H}$, et al: Targeting the IGF-1R using picropodophyllin in the therapeutical 5T2MM mouse model of multiple myeloma: beneficial effects on tumor growth, angiogenesis, bone disease and survival. Int $\mathbf{J}$ Cancer 121: 1857-1861, 2007.

64. Vasilcanu R, Vasilcanu D, Rosengren L, Natalishvili N, Sehat B, Yin S, Girnita A, Axelson M, Girnita L and Larsson O: Picropodophyllin induces downregulation of the insulin-like growth factor 1 receptor: potential mechanistic involvement of Mdm2 and beta-arrestin1. Oncogene 27: 1629-1638, 2008.

65. Vasilcanu R, Vasilcanu D, Sehat B, Yin S, Girnita A, Axelson M and Girnita L: Insulin-like growth factor type-I receptor-dependent phosphorylation of extracellular signal-regulated kinase $1 / 2$ but not Akt (protein kinase B) can be induced by picropodophyllin. Mol Pharmacol 73: 930-939, 2008.

66. Linder S, Shoshan MC and Gupta RS: Picropodophyllotoxin or podophyllotoxin does not induce cell death via insulin-like growth factor-I receptor. Cancer Res 67: 2899-2900, 2007. 